\title{
Antioxidant Enzyme Activities of Kiwifruit Seedlings 'Watt' and 'Hayward' to Salt Stress
}

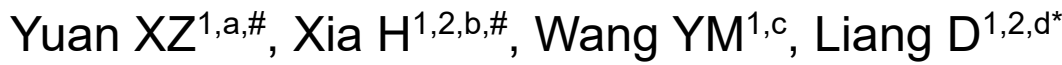 \\ ${ }^{1}$ College of Horticulture, Sichuan Agricultural University, Chengdu 611130, China; \\ 2 Institute of Pomology and Olericulture, Sichuan Agricultural University, Chengdu 611130, China \\ a1723065255@qq.com, b381683619@qq.com ,c1336489390@qq.com, d756141959@qq.com \\ ${ }^{\#}$ Co-first author, *Corresponding author
}

Key words: kiwifruit; salt stress; salt injury index; resistance index; salt tolerance

Abstract: Kiwifruit seedlings of two cultivars 'Watt' and 'Hayward' were used as materials to compare their antioxidant enzyme activities under $100 \mathrm{mmol} \cdot \mathrm{L}^{-1} \mathrm{NaCl}$ stress. The results showed that under salt stress, and superoxide dismutase (SOD) activity in both cultivars leaves were all showed an upward trend; and the soluble protein and hydrogen peroxide $\left(\mathrm{H}_{2} \mathrm{O}_{2}\right)$ content increased at earlier stage, but fall at later stage. During the whole process, the relative conductance and MDA content in 'Watt' were significantly lower than these in 'Hayward', indicating that 'Watt' had stronger tolerance to salt stress than 'Hayward'. While 'Hayward' had significantly higher SOD enzyme activity, but lower $\mathrm{H}_{2} \mathrm{O}_{2}$ content than 'Watt', indicating effectively activated the stress response in 'Hayward'.

\section{Introduction}

Soil salinization is a global problem. Salts in saline-alkali soil are mainly composed of 3 kinds of ions, $\mathrm{Na}^{+}, \mathrm{Ca}^{2+}$ and $\mathrm{Mg}^{2+}$, and 4 types of anions, $\mathrm{CO}_{3}{ }^{2-}, \mathrm{HCO}_{3}{ }^{-}, \mathrm{Cl}^{-}$, and $\mathrm{SO}_{4}{ }^{2-}$. Among the existing large-area salinized land in China, the sodium salt is the main salt in soil ${ }^{[1]}$. The stress caused by sodium salt can induce osmotic stress, ion stress and oxidative stress of plant seedlings, thereby accelerating membrane lipid peroxidation, accumulating harmful substances, causing metabolic disorders, and seriously affecting the normal physiological activities of plants ${ }^{[2-3]}$.

Kiwifruit belongs to Actinidiaceae Family, Actinidia genus, and among total 66 species, 62 are native to China ${ }^{[4]}$. Kiwifruits, known as the "King of $\mathrm{V}_{\mathrm{C}}$ ", are rich in trace elements, amino acids, vitamin $\mathrm{C}\left(\mathrm{V}_{\mathrm{C}}\right)^{[5]}$. The increasing consumption of kiwifruit in China has greatly stimulated the development of kiwifruit cultivation and production. However, salt tolerance evaluation of 18 kinds of fruit trees showed that kiwifruit ranked 17th, belonging to the less salt-tolerant tree, according to research of Ma Kai et al. ${ }^{[6]}$. In this study, two varieties of kiwifruit seedlings were used as materials to compare the salt tolerance under salt stress, which will provide theoretical basis for the production of kiwifruit on the saline-alkali soil and the selection of rootstocks.

\section{Materials and Methods}

Material Preparation. The seeds were collected from ripen kiwifruit, and kept dry. In January, a smooth and full kiwifruit was selected and sterilized by soaking in 5\% sodium hypochlorite solution for 5 minutes, and then stored at $4{ }^{\circ} \mathrm{C}$ for 2 months. After poikilothermic treatment at $25{ }^{\circ} \mathrm{C} / 4{ }^{\circ} \mathrm{C}(8$ $\mathrm{h} / 16 \mathrm{~h})$ for 2 weeks, seeds were placed in a $25 \pm 1{ }^{\circ} \mathrm{C}(12 \mathrm{~h} / 12 \mathrm{~h})$ incubator for germination. The germinated seeds were sown in seedling disks with mixed soil (peat soil: vermiculite: perlite $=3: 1: 1$ ). At three true leaf stages, every 3 seedlings were transplanted into a $23 \mathrm{~cm} \times 18 \mathrm{~cm}$ pot placed in the culturing chamber with temperature at $25 \pm 1{ }^{\circ} \mathrm{C}$, and light $12 \mathrm{~h} / 12 \mathrm{~h} .1 / 2$ Hoagland nutrient solution is applied every 2 days.

Plant treatment. When the seedlings grew to 8 true leaves, uniform seedlings were selected and transferred into a $40 \mathrm{~cm} \times 35 \mathrm{~cm} \times 15 \mathrm{~cm}$ water culture box with $1 / 2$ Hoagland nutrient solution for one week pre-cultivation, then treated with $100 \mathrm{mmol} \cdot \mathrm{L}^{-1} \mathrm{NaCl} .2$ boxes for each repeat, and repeated 3 times. samples were collected from the 3rd to 6th true leaves at 9:00 am on the 0th, 1st, 2nd, 3rd, 
and 4th day of $\mathrm{NaCl}$ treatment, then frozen in liquid nitrogen and stored at $-80{ }^{\circ} \mathrm{C}$ for late determination.

Indicator measurement. $\mathrm{H}_{2} \mathrm{O}_{2}$ content was determined by the method of Hao et al. ${ }^{[7]}$; relative conductance, soluble protein content, MDA content, SOD, POD and CAT activity were measured with reference to Li's Method ${ }^{[8]}$.

Data analysis. Excel 2010 was used for data processing and charting, SPSS 20.0 was used for significance analysis by one-way variance and Duncan method.

\section{Results and Analysis}

$\mathrm{H}_{2} \mathrm{O}_{2}$ Content under salt stress. As shown in Fig. 1, the $\mathrm{H}_{2} \mathrm{O}_{2}$ content in leaves of 'Watt' seedlings increased significantly from 0 to $2 \mathrm{~d}$ during the stress period, and reached the maximum at the $2 \mathrm{~d}$ $\left(227.61 \mathrm{Umol} \cdot \mathrm{g}^{-1}\right)$, which was 2.86 times that of $0 \mathrm{~d}$., then showed a significant downward trend. The $\mathrm{H}_{2} \mathrm{O}_{2}$ content of 'Hayward' seedling leaves rise first and then fall and again. It reached the maximum value $\left(199.77 \mathrm{Umol}^{\circ} \mathrm{g}^{-1}\right)$ at the $3 \mathrm{~d}$, which was 5.87 times that of $0 \mathrm{~d}$. During the whole period of stress, the contents of $\mathrm{H}_{2} \mathrm{O}_{2}$ in leaves of two kiwifruit cultivars were greater than $0 \mathrm{~d}$. The $\mathrm{H}_{2} \mathrm{O}_{2}$ content in leaves of 'Watt' seedlings was significantly higher than that of 'Hayward' on 0-2 d, but was significantly lower than 'Watt' on $3 \mathrm{~d}$. In summary, the $\mathrm{H}_{2} \mathrm{O}_{2}$ content in the leaves of 'Hayward' seedlings is more obvious during the stress period.

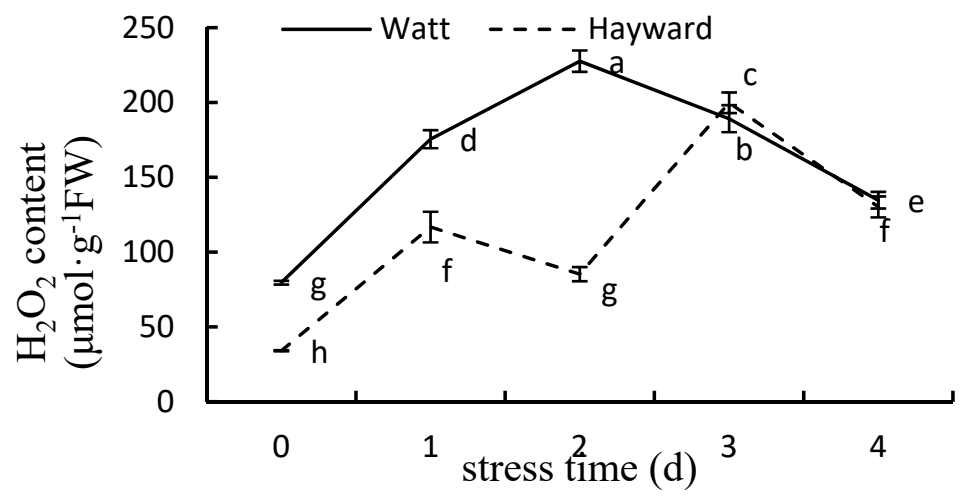

Figure. 1 Effect of $\mathrm{NaCl}$ treatment on $\mathrm{H}_{2} \mathrm{O}_{2}$ content in seedling leaves

Antioxidant Enzyme Activity of SOD under salt stress. Salt stress will produce a large amount of reactive oxygen species and $\mathrm{H}_{2} \mathrm{O}_{2}$ in the leaves of kiwifruit seedlings. SOD, POD and CAT are the main enzymes that remove excess $\mathrm{H}_{2} \mathrm{O}_{2}$ from the plants, and play an important role in maintaining the level of reactive oxygen species in the cells. As shown in Fig. 6, during the stress period, the SOD activity in 'Watt' leaves showed an increasing trend and reached a maximum at $4 \mathrm{~d}(208.65$ $\mathrm{U} \cdot \mathrm{g}^{-1} \cdot \mathrm{min}^{-1}$ ), which was 3.82 times of that at $0 \mathrm{~d}$. 'Hayward' first declined and then rose, reaching a minimum value at $2 \mathrm{~d}$ and reaching a maximum value of $495.20 \mathrm{U} \cdot \mathrm{g}^{-1} \cdot \mathrm{min}^{-1}$ at $4 \mathrm{~d}$, which was 1.89 times higher than $0 \mathrm{~d}$. Overall, the SOD activity in 'Watt' seedling leaves was significantly lower than that in 'Hayward'.

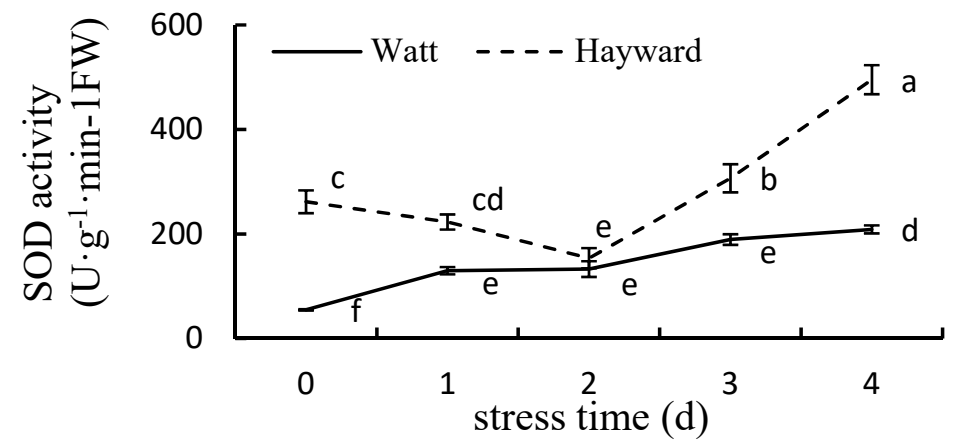

Figure 2 Effect of $\mathrm{NaCl}$ treatment on SOD activity in kiwifruit seedling

Antioxidant Enzyme Activity of POD under salt stress. As shown in Fig. 3, during the stress 
period, the POD activity in 'Watt' leaves didn't change significantly before $2 \mathrm{~d}$, but then decreased rapid, and reached the minimum value at $3 \mathrm{~d}\left(1578.96 \mathrm{U} \cdot \mathrm{g}^{-1} \cdot \mathrm{min}^{-1}\right)$, which was 0.37 times of $0 \mathrm{~d}$, and $4 \mathrm{~d}$ increased to $0 \mathrm{~d}$ 's level. While the trend of 'Hayward' shown the opposite to 'Watt', reaching a maximum at $3 \mathrm{~d}\left(5310.93 \mathrm{U} \cdot \mathrm{g}^{-1} \cdot \mathrm{min}^{-1}\right), 4.03$ times $0 \mathrm{~d}$. Overall, the POD activity in 'Watt' was significantly lower than that in 'Hayward'.

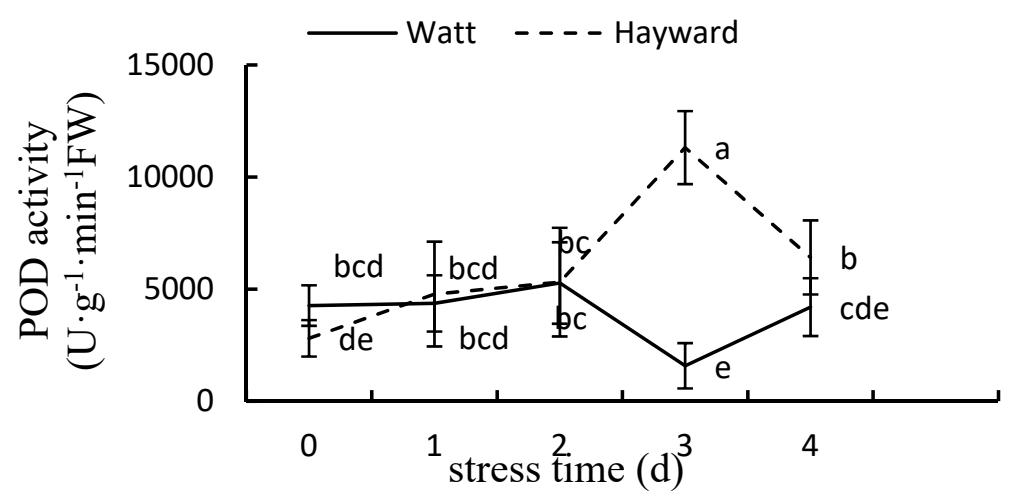

Figure 3 Effect of $\mathrm{NaCl}$ treatment on POD activity in seedling leaves.

Antioxidant Enzyme Activity of CAT under salt stress. As shown in Fig. 4, during the stress period, the CAT activity of leaves of 'Watt' seedlings was not significantly different from $1 \mathrm{~d}$ to $4 \mathrm{~d}$, and reached the maximum value $\left(30 \mathrm{U} \cdot \mathrm{g}^{-1} \cdot \mathrm{min}^{-1}\right)$ at $0 \mathrm{~d}$, which was 2.26 times at $4 \mathrm{~d}$., while the trend of 'Hayward' was basically the opposite, the difference was not significant on 1-4 d, $0 \mathrm{~d}$ reached the minimum $\left(7.30 \mathrm{U} \cdot \mathrm{g}^{-1} \cdot \mathrm{min}^{-1}\right)$, which was 0.55 times that of $4 \mathrm{~d}$. Overall, the CAT activity of 'Watt' seedling leaves was significantly higher than that of 'Hayward'.

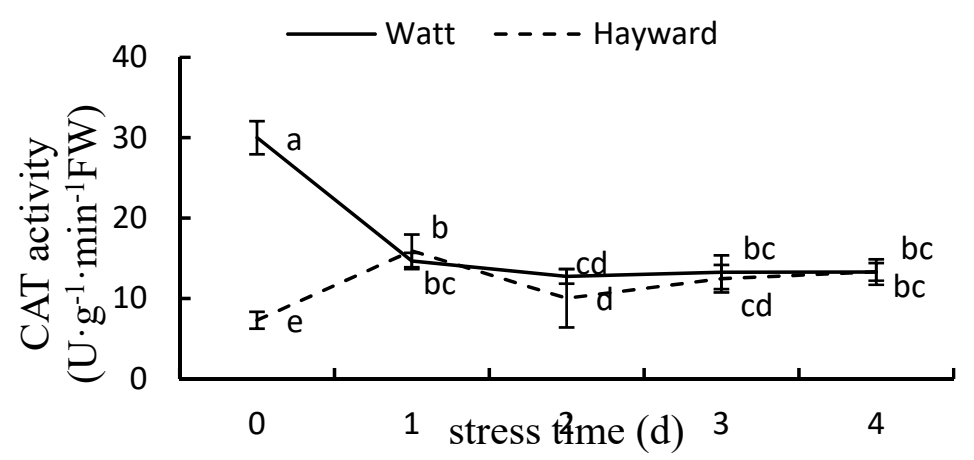

Figure 4 Effect of $\mathrm{NaCl}$ treatment on CAT activity in seedling leaves.

\section{Discussion}

The amount of chlorophyll does not only determine the photosynthetic efficiency of the plant, but also sometimes measures the salt tolerance of the plant. In this experiment, during the period of stress, the two kiwifruit varieties showed an overall increase in the chlorophyll content of the seedling leaves. This may be due to the fact that under the salt concentration $\left(100 \mathrm{mmol} \cdot \mathrm{L}^{-1} \mathrm{NaCl}\right)$, 'Watt' and 'Hayward' The self-regulatory ability of the seedling leaves is strong, and in order to maintain their normal level of photosynthesis, the synthesis of chlorophyll is accelerated, thereby improving its salt tolerance.

SOD, POD and CAT are three important antioxidant enzymes in the plant body. Under stress conditions, maintaining high activity level, the plant can resist the damage caused by a certain degree of stress. In this experiment, the activities of SOD and POD in leaves of 'Watt' seedlings were significantly lower than in 'Hayward'. The CAT activities in leaves of 'Watt' seedlings were significantly higher than those in 'Hayward', and the POD and CAT activities showed opposite trends. Overall, the trend of changes in $\mathrm{H}_{2} \mathrm{O}_{2}$ content in leaves of seedlings was consistent.

In summary, under the stress of $100 \mathrm{mmol} \cdot \mathrm{L}^{-1} \mathrm{NaCl}$, 'Watt' had parent stronger salt tolerance than 'Hayward'. 


\section{Acknowledgements}

This work was financially supported by the Sichuan Technical Supports Foundation (2016NZ0105) and Training Programs of Innovation for Undergraduates in Sichuan (201610626057).

\section{References}

[1] Zhao Y, Liu ZM, Zhou H. Pineal body and melatonin [M]. Shanghai: Shanghai Scientific and Technical Literature Press, 2004.

[2] Wang XQ. Studies on the metabolism of phenolics in red meat and its response to adversity [D]. Yang Ling, Northwest A\&F University, 2015.

[3] Zhang H. Establishment and application of a rapid and highly efficient on-line antioxidant activity evaluation method for citrus fruits[D]. Chongqing: Southwest University, 2014.

[4] Zhang H. Biological characteristics and fruit development of Actinidia chinensis "Beimu" [D]. Jishou University, 2017.

[5] Chen D, Yang JS. Soil Saline Environment and Nutrient Management[J]. Advances in Posozoology, 1995, 23(5): 7-13.

[6] Yan Q. Kiwifruit in China[J]. Academic Journal: e-edition, 2016(13):183-184.

[7] Ma Kai, Wang LB, Wang YB. Eighteen species of salt damage and salt tolerance in fruit trees[J]. JOURNAL OF fruit trees, 1997, 14(1): 1-5.

[8] Gao JF. Plant Physiology Technology[M]. World Book Publishing House, 2000:387-384. 